\title{
Estado, capital e dinâmicas de internacionalização produtiva
}

Leandro Bruno Santos e Erika Vanessa Moreira Santos

\section{(2) OpenEdition}

1 Journals

\section{Edição electrónica}

URL: http://journals.openedition.org/espacoeconomia/18093

DOI: 10.4000/espacoeconomia.18093

ISSN: 2317-7837

\section{Editora}

Núcleo de Pesquisa Espaço \& Economia

\section{Refêrencia eletrónica}

Leandro Bruno Santos e Erika Vanessa Moreira Santos, «Estado, capital e dinâmicas de internacionalização produtiva», Espaço e Economia [Online], 20 | 2020, posto online no dia 28 dezembro 2020, consultado o 29 janeiro 2021. URL: http://journals.openedition.org/espacoeconomia/ 18093 ; DOI: https://doi.org/10.4000/espacoeconomia.18093

\section{Este documento foi criado de forma automática no dia 29 janeiro 2021.}

\section{c) (1) 8 ()}

Espaço e Economia - Revista brasileira de geografia econômica est mise à disposition selon les termes de la licence Creative Commons Attribution - Pas d'Utilisation Commerciale - Partage dans les Mêmes Conditions 4.0 International. 


\title{
Estado, capital e dinâmicas de internacionalização produtiva
}

\author{
Leandro Bruno Santos e Erika Vanessa Moreira Santos
}

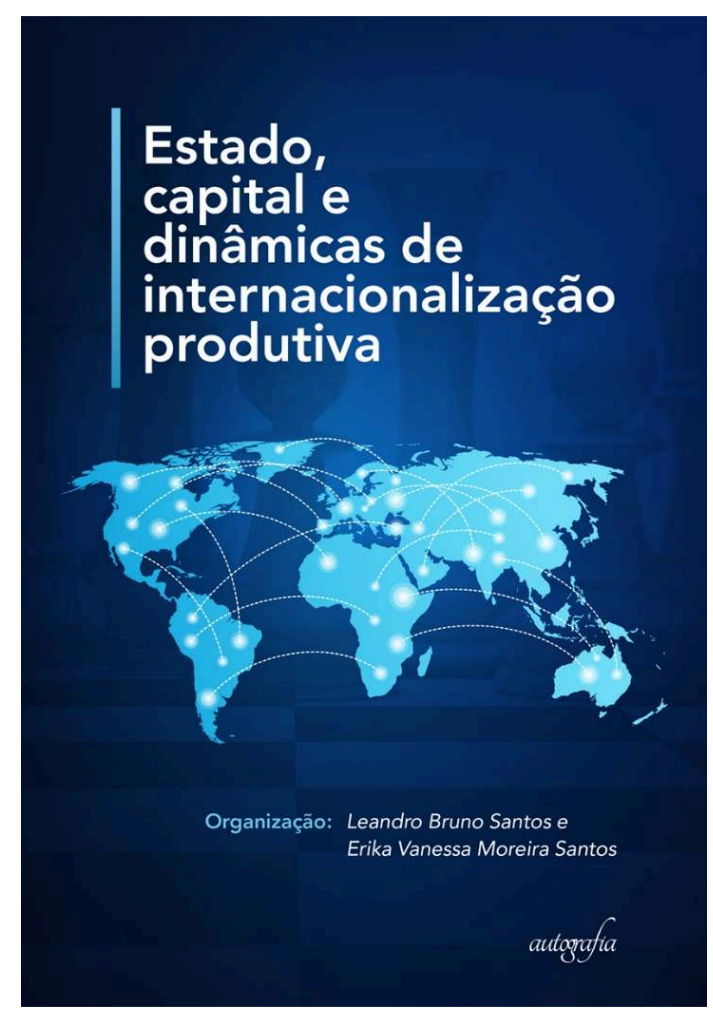

1 Estado, capital e dinâmicas de internacionalização produtiva, organizado pelos professores Erika Vanessa Moreira Santos e Leandro Bruno santos, da Universidade Federal Fluminense - Campos dos Goytacazes, é resultado do workshop intitulado "Estado e Internacionalização de Empresas", realizado em 14 de novembro de 2017, nas dependências da Universidade Federal Fluminense (UFF), Campos dos Goytacazes. Naquela ocasião, o evento contou com a participação de 97 alunos de graduação e pós- 
graduação provenientes da UFF, do Instituto Federal Fluminense (IFF) e da Universidade Cândido Mendes (UCAM), além de servidores e professores do Instituto.

Durante o evento foram realizadas sete palestras que abordaram a dependência e o desenvolvimento nos governos do Partido dos Trabalhadores (PT) no Brasil, as diferentes correntes da economia política internacional, o movimento das frações do capital e suas repercussões nas redes globais e no capitalismo contemporâneo, a internacionalização de empresas brasileiras e o desenvolvimento econômico, o Estado e a internacionalização de empresas, as articulações entre Estado e as estratégias de desenvolvimento e internacionalização das grandes empresas no Brasil e no México e a atuação do BNDES no processo de internacionalização de empresas brasileiras.

3 As palestras foram proferidas por pesquisadores de diferentes instituições (Universidade Estadual Paulista, Instituto Federal Fluminense, Universidade Federal Fluminense, Secretaria de Estado de Educação do Rio de Janeiro), com formação acadêmica diversa, envolvendo Geografia, Economia, Ciência Política e História Econômica. As temáticas abordadas revelam a importância da interdisciplinaridade nos estudos das inter-relações Estado e Economia, particularmente quando abordamos as estratégias de internacionalização produtiva dos capitais e suas frações.

4 Após a realização do workshop, como sois acontecer, houve um esforço para reunir as contribuições sob a forma de papers e viabilizar a publicação. 0 livro está dividido em sete capítulos. Eles foram distribuídos seguindo diferentes mediações e concreções, numa direção das análises mais gerais para aquelas mais concretas. A temática não se esgota por aqui, pelo contrário, mais esforços são necessários para compreender as inter-relações dinâmicas entre Estado e empresas na internacionalização produtiva à luz de uma economia política.

Por último, mas não menos importante, o evento e os resultados sob a forma de livro não teriam sido possíveis sem o apoio da Pró-Reitoria de Pesquisa, Pós-Graduação e Inovação (PROPPI), por meio do Edital FOPESQ/2017, do Instituto de Ciências da Sociedade e Desenvolvimento Regional (ESR)/UFF, oferecendo apoio logístico e infraestrutura, e das alunas e dos alunos do Núcleo de Estudos em Economia Política Geográfica (NEEPG) e do Núcleo de Estudos Rurais e Urbanos (NERU), que apoiaram incansavelmente a realização do workshop.

\section{Referência}

SANTOS, Leandro Bruno; SANTOS, Erika Vanessa Moreira Santos. Estado, capital e dinâmicas de internacionalização produtiva. Rio de Janeiro, RJ: Autografia, 2020.

ISBN: 978-65-5531-422-9. 


\section{AUTORES}

\section{LEANDRO BRUNO SANTOS}

Possui licenciatura e bacharelado em Geografia pela Universidade Estadual Paulista Júlio de Mesquita Filho, Faculdade de Ciências e Tecnologia, campus de Presidente Prudente (2005). É mestre (2008) e doutor (2012) pelo Programa de Pós-Graduação em Geografia pela Faculdade de Ciências e Tecnologia, Universidade Estadual Paulista Júlio de Mesquita Filho, com estágio sanduíche na Benemérita Univerdad Autónoma de Puebla (BUAP). Foi professor assistente doutor, entre 2013 e 2015, da Universidade Estadual Paulista (UNESP), campus de Ourinhos. Atualmente é professor adjunto do curso de Geografia, Instituto de Ciências da Sociedade e Desenvolvimento Regional (ESR), Universidade Federal Fluminense (UFF). É também credenciado como docente permanente no Programa de Pós-Graduação em Geografia (PPG) no ESR/UFF. Coordena o Núcleo de Estudos em Economia Política Geográfica (NEEPG). Tem experiência na área de Geografia, com ênfase em Geografia Econômica e Geografia Industrial, atuando principalmente nos seguintes temas: Estado; mundialização; empresas multinacionais; investimentos diretos estrangeiros. É Jovem Cientista do Nosso Estado (JCNE), pela Fundação de Amparo à Pesquisa do Estado do Rio de Janeiro - FAPERJ, e Bolsista Produtividade do CNPq. Email: leandrobruno@id.uff.br.

\section{ERIKA VANESSA MOREIRA SANTOS}

Doutora em Geografia pela Universidade Estadual Paulista - UNESP de Presidente Prudente/SP. Concluiu a graduação em 2003 e o mestrado em 2007. Desenvolve pesquisa na área de Geografia Humana, Rural e Regional. Trabalha com os seguintes temas: rural-urbano; ruralidade; mioloestadocapitaledinamicas.indd 228 8/26/2020 11:09:05 229 agricultura familiar; bairros rurais; agricultura urbana. Realizou, no ano de 2011, estágio de doutorado - missão de estudo, na Universidade de Havana, como parte de um Projeto de Cooperação Brasil-Cuba da CAPES. Atualmente, é professora adjunta II da Universidade Federal Fluminense, Departamento de Geografia de Campo e do Programa de Pós-Graduação em Geografia UFF/Campos. E-mail: erikamoreira@id.uff.br. 